\title{
Fracture Strength of Composite Fixed Partial Denture Using Bovine Teeth as a Substitute for Human Teeth With or Without Fiber-Reinforcement
}

\author{
Carlos José SOARES ${ }^{1}$ \\ Liliane Minglini BARBOSA ${ }^{1}$ \\ Fernanda Ribeiro SANTANA ${ }^{1}$ \\ Priscilla Barbosa Ferreira SOARES ${ }^{2}$ \\ Adérito Soares da MOTA ${ }^{3}$ \\ Gisele Rodrigues da SILVA ${ }^{1}$ \begin{abstract}
Federal University of Uberlândia, Uberlândia, $M G$, Brazil
${ }^{2}$ Department of Periodontology and Implantology, Dental School, Federal University of Uberlândia, Uberlândia, $M G$, Brazil

${ }^{3}$ Department of Occlusion and Fixed Prosthodontics, Dental School, Federal University of Uberlândia, Uberlândia, $M G$, Brazil
\end{abstract} \\ ${ }^{1}$ Department of Operative Dentistry and Dental Materials, Dental School,
}

\begin{abstract}
This study evaluate the use of bovine teeth as a substitute for human teeth on fracture strength tests of composite fixed partial dentures (Cpd), with and without fiberglass reinforcement (Fg). Eighty teeth were selected, being 40 bovine incisors, 20 human premolars and 20 molars. Bovine incisors were ground to get a platform, simulating an occlusal surface of human molar. Teeth in pairs were embedded in polystyrene resin, simulating the periodontal ligament and divided in 4 groups: B-Cpd-Fg: bovine teeth restored with Cpd with Fg; B-Cpd-NFg: bovine teeth restored with Cpd without Fg; H-Cpd-Fg: human teeth restored Cpd with Fg; and H-Cpd-NFg: human teeth restored with Cpd without Fg. The Cpd were adhesively fixed and submitted to an axial compression load at the pontic center with a crosshead speed of $0.5 \mathrm{~mm} / \mathrm{min}$ until fracture. Failure modes were assessed and classified. Data were subjected to two-way ANOVA and Tukey's HSD test $(\alpha=0.05)$. The tooth type had no influence on fracture strength and fracture mode. The inclusion of fiberglass increased significantly the fracture strength. The failure modes were more reparable in groups with fiber-reinforcement. Bovine teeth can be used as a substitute for human teeth in these types of fracture strength tests.
\end{abstract}

Key Words: glass fiber, composite partial denture, human teeth, bovine teeth, fracture strength.

\section{INTRODUCTION}

The establishment of hybrid layer and evolution of adhesive systems have allowed the accomplishment of restorative adhesive procedures as an alternative treatment option for conventional techniques. The prevention in dentistry increased difficulty to obtain sound human teeth for dental researches (1). In addition, the ethics committees' requirement of an informed consent from the donors has made it even more difficult (1). Different hard tissues have been used in an attempt to find an adequate substitute for human teeth in dental research, such as teeth from dogs, monkeys, swine and bovine (1-3). However, is also necessary to establish standardized parameters, such as type of feeding and age, prior to the collection of animal teeth (2). Bovine and porcine teeth are easier to obtain compared to other animals' teeth, and the age of the animal can also be easy controlled (1). Bovine teeth are the most frequently used in laboratory research at present because of its ready availability, absence of carious and present good size, which facilitates technical procedures (3). Bovine permanent incisors have been used on adhesion tests $(1,4)$, microleakage tests (5), fracture tests (3), trace element 
studies (18), analysis of morphologic characteristics (6), and permeability tests (7), as a substitute for human teeth. However, there is no study comparing the use of bovine and human teeth for the analysis of fracture strength of fiber-reinforced composite fixed partial denture.

The development and consequent success of fiberreinforced composite (FRC) has become an attractive alternative to conventional metal-supported fixed partial denture (8). The use of minimally invasive preparation protocols has reduced the loss of sound dental structure. The FRC system is composed of a load-bearing fiber framework and a veneering composite with highly filled particles. The most commonly used FRCs consists of glass-fibers embedded in a dimethacrylate resin matrix. The fracture strength ability of FRC depends on the amount of the fiber glass and the interaction between the polymer matrix and the fibers (7-9). Due to enhanced mechanical properties and wear strength, composites are used even in posterior dental restorations (8).

Although the fiber reinforcement of composite partial denture has been evaluated (7-9), it is still necessary to study an alternative to be used in the place of human teeth in fracture strength testing of fiberglassreinforced composite partial dentures. Therefore, the purposes of the present investigation were to determine the influence of fiber reinforcement on fracture strength of composite partial denture, and to validate the use of bovine teeth as a substitute for human teeth. The null hypotheses were that fiber reinforcement does not influence the fracture strength of composite partial denture, and that bovine teeth are not a substitute for human teeth in fracture strength test of composite partial denture.

\section{MATERIAL AND METHODS}

Forty intact bovine incisors, 20 intact premolars and 20 intact second mandibular molars, with a similar size into each group of teeth were selected. The time from extraction to mechanical test of teeth was less than 3 months. Teeth were stored in distilled water and $0.2 \%$ thymol solution at $37^{\circ} \mathrm{C}$. Bovine teeth were grounded with \#600-grit silicon carbide paper (Norton, Campinas, SP, Brazil) to get an incisor platform, simulating an occlusal surface of human molar. The teeth were embedded in pairs, being 1 molar and 1 premolar, or 2 bovine incisors, at a distance of $2.0 \mathrm{~mm}$ from the cementoenamel junction using polystyrene resin (Cromitec, Piracicaba, SP, Brazil). A distance between both teeth was established at $11.0 \mathrm{~mm}$, which represent the mean mesiodistal length of a first human molar. Periodontal ligaments were simulated inside the cylinder using a polyether impression material (Impregum F; 3M/ESPE, St. Paul, MN, USA) to simulate physiological tooth mobility (10).

The cavities were prepared with specific diamond burs (\#2131; KG Sorensen, Barueri, SP, Brazil) at high speed and under air-water spray cooling, using a standard cavity preparation machine. The dimensions were measured by a digital caliper (Mitutoyo CD15; Mitutoyo Co., Kawasaki, Honshu, Japan). Standardized mesial-occlusal (MO) and occlusal-distal (OD) cavities were prepared for all pairs of teeth at high speed and under air-water spray cooling. The dimensions of the MO cavity were: $4.0 \mathrm{~mm}$-buccolingual, $4.0 \mathrm{~mm}$ mesiodistal, $2.5 \mathrm{~mm}$ deep. The dimensions of the OD cavity were: $4.0 \mathrm{~mm}$-buccolingual, $6.0 \mathrm{~mm}$-mesiodistal, $2.5 \mathrm{~mm}$ deep. The proximal box for both preparations presented $2.0 \mathrm{~mm}$ - mesiodistal and extending $1.5 \mathrm{~mm}$ apical to the gingival wall. Four groups (Fig. 1A-1D) were obtained $(\mathrm{n}=10)$ : B-Cpd-Fg: bovine teeth restored with composite partial denture $(\mathrm{Cpd})$ with fiberglass reinforcement (Fg) (Interlig; Angelus, Londrina, PR, Brazil); B-Cpd-NFg: bovine teeth restored with Cpd without Fg; H-Cpd-Fg: human teeth restored with $\mathrm{Cpd}$ with Fg (Interlig; Angelus); and H-Cpd-NFg: human teeth restored with $\mathrm{Cpd}$ without $\mathrm{Fg}$.

A single-stage impression was made of each prepared tooth using a double-viscosity vinyl polysiloxane (Adsil; Vigodent, Rio de Janeiro, RJ, Brazil) in a stock plastic tray (Tigre, São Paulo, SP, Brazil). After $2 \mathrm{~h}$, the impressions were poured with Type IV stone (Velmix; Kerr Italy Spa, Scafati, Italy). One technician

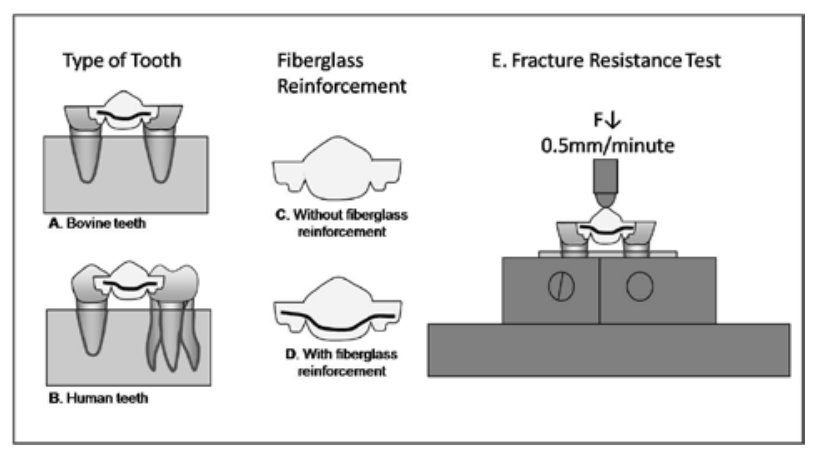

Figure 1. Schematic view of procedures. Type of tooth factor: A. bovine teeth, B. Human Teeth embedded tooth simulating periodontal ligament. Fiberglass reinforcement factor: C. Without fiberglass reinforcement, D. With fiberglass reinforcement. E. Fracture resistance test. 
fabricated all restorations using a standardized technique and following the manufacturer's instructions. A spacer (Nice Fit, Gold; Shofu, Inc, Kyoto, Japan) was applied over the high-density stone dies. To standardize the restoration a transparent matrix was used to reproduce the geometry of the pontic. For groups B-Cpd-NFg and $\mathrm{H}-\mathrm{Cpd}-\mathrm{NFg}$ the restoration was made incrementally. A 1.0-mm-thick increment of Z100 composite resin (3M/ ESPE) was inserted and polymerized with a LED source (Radii-cal; SDI, São Paulo, SP, Brazil) with light intensity of $1,400 \mathrm{~mW} / \mathrm{cm}^{2}$ for $40 \mathrm{~s}$. For groups B-Cpd-Fg and $\mathrm{H}-\mathrm{Cpd}-\mathrm{Fg}$, a single composite resin-impregnated fiberglass framework (Interlig; Angelus) was used. A 1.0-mm-thick of composite resin Z100 was inserted and the framework was inserted and polymerized with the LED source (Radii-cal; SDI) for $40 \mathrm{~s}$. The restorations were completed in the same way as described for the other groups. Post-polymerization was done in autoclave for $15 \mathrm{~min}$ at $100^{\circ} \mathrm{C}$ for all groups (11).

According to the total-etch technique, the inlay cavities were etched with 35\% phosphoric acid (Scotch Etchant; 3M/ESPE) for $15 \mathrm{~s}$, rinsed with water, and blotted dry with a dry paper. The adhesive system (Adper ScothBond Multi Purpose; 3M/ESPE) was applied according protocol proposed by Dong et al., 2003 (12). Two primer coats were applied, and then waited $20 \mathrm{~s}$ before air drying. After it, it was applied 1 coat of adhesive, and then waited $20 \mathrm{~s}$ before air drying, and polymerized for $10 \mathrm{~s}$ with the LED source (Radii-cal; SDI) with light intensity of $1400 \mathrm{~mW} / \mathrm{cm}^{2}$. The intaglio surface of composite inlay AFPDs were sandblasted with $50 \mu \mathrm{m}$ aluminum oxide abrasive particle and pressure of $1 \mathrm{bar}$ (Bioart, São Paulo, SP, Brazil) for $10 \mathrm{~s}$ and silanated (Ceramic Primer; 3M/ESPE) before cementation. Adual cure resin cement (Rely-X ARC; 3M/ESPE) was mixed and applied to the internal surfaces of the restorations.

Table 1. Mean fracture strength (SD) values $(\mathrm{N})$ and statistical categories defined by Tukey HSD test for interaction between type of teeth and fiber-reinforcement presence $(n=10)$.

\begin{tabular}{lcc}
\hline & Bovine teeth & Human teeth \\
\hline $\begin{array}{l}\text { Fiber- } \\
\text { reinforcement }\end{array}$ & $88.4(21.7)^{\mathrm{Aa}}$ & $93.9(23.1)^{\mathrm{Aa}}$ \\
$\begin{array}{l}\text { No fiber- } \\
\text { reinforcement }\end{array}$ & $68.6(16.5)^{\mathrm{Ab}}$ & $72.1(13.3)^{\mathrm{Ab}}$ \\
\hline
\end{tabular}

Different uppercase letter (comparison in columns: type of teeth) or lowercase letter (comparison in lines: fiber-reinforcement presence) indicate significant differences $(\mathrm{p}<0.05)$.
Next, an occlusal load of $500 \mathrm{~g}$ for 5 min was applied on the restoration, the excess cement was removed with a brush (Cavibrush; FGM, Joinville, SC, Brazil) and the material was polymerized for $40 \mathrm{~s}$ with the LED source (Radii-cal; SDI) from the occlusal, mesiobuccal and mesiolingual surfaces.

After storage in distilled water at $37^{\circ} \mathrm{C}$ for $24 \mathrm{~h}$, the specimens were subjected to a compressive load with a 6-mm-diameter steel sphere contacting the center of the occlusal surface of the pontic in a universal testing machine (Emic DL-2000; EMIC, São José dos Pinhais, PR, Brazil) at a crosshead speed of $0.5 \mathrm{~mm} / \mathrm{min}$ (Fig. 1E). The axial compressive load at fracture, identified as the initial tooth crack, was recorded for each specimen $(\mathrm{N})$. After the compressive test, the failure mode for each tooth specimen was classified according to 4 categories: type I, fracture of the pontic; type II, partial fracture in the connector and pontic; type III, total fracture of the abutment; type IV, fracture involving dental structure. The fracture strength data were subjected to statistical analysis by two-way ANOVA and Tukey's HSD test $(\alpha=0.05)$.

\section{RESULTS}

Table 1 shows the ultimate fracture strength and standard deviations for all groups. Two-way ANOVA indicated that there was significant differences between groups only for the fiber reinforcement factor $(p<0.05)$. The tooth type did not significantly influence the fracture strength. The Tukey's HSD test showed that groups with fiberglass reinforcement exhibited significantly higher mean fracture strength $(p<0.05)$ than those without fiberglass, irrespective of the tooth type (Table 1).

The analysis of the failure modes is summarized

Table 2. Specimen distribution according to the failure mode.

\begin{tabular}{lccccc}
\hline \multirow{2}{*}{$\begin{array}{c}\text { Froups } \\
\text { reinforcement }\end{array}$} & $\begin{array}{c}\text { Type } \\
\text { I }\end{array}$ & $\begin{array}{c}\text { Type } \\
\text { II }\end{array}$ & $\begin{array}{c}\text { Type } \\
\text { III }\end{array}$ & $\begin{array}{c}\text { Type } \\
\text { IV }\end{array}$ \\
$\begin{array}{l}\text { Bovine } \\
\text { teeth }\end{array}$ & Yes & - & 6 & 4 & - \\
& No & - & 1 & 9 & - \\
& & & & & \\
$\begin{array}{l}\text { Human } \\
\text { teeth }\end{array}$ & Yes & - & 7 & 3 & - \\
& No & - & - & 10 & - \\
\hline
\end{tabular}


in Table 2. For both type of teeth restored with fiberglass reinforcement (B-Cpd-Fg and $\mathrm{H}-\mathrm{Cpd}-\mathrm{Fg}$ ), the prevalent fracture mode was type II, while in groups without fiberglass reinforcement (B-Cpd-NFg and $\mathrm{H}-\mathrm{Cpd}-\mathrm{NFg}$ ) the fracture pattern was mainly of type III. No fracture involving dental structure was observed in any group.

\section{DISCUSSION}

The null hypotheses were rejected. The results of the present study indicated that fiberglass reinforcement influenced significantly the composite inlay fracture strength of composite partial denture. However, no significant difference was found between the fracture strength of bovine and human teeth. To justify the possible reasons for this similarity, factors such as variables of dental structure (composition and morphology), restorative material (composition and arrangement) and how the dental structure relates with restorative material (preparation characteristics, mechanical retention and adhesion) must be analyzed.

As far as the dental structure is concerned, despite some structural differences between bovine and human teeth $(5,14)$, several studies $(1,4)$ consider bovine teeth as possible substitutes for human teeth in dentin or enamel bond testing. Histochemical and comparative morphological studies have revealed that all mammalian teeth are essentially similar (13). According to Schilke et al. (4), mid-depth bovine and human dentin have similar number and diameter of coronal dentin tubules. Reis et al. (1), showed by scanning electron microscopy that human and bovine coronal dentin substrates are very much alike with regard to number and diameter of tubules in mid-depth dentin, and the comparison of enamel morphology after acid etching revealed that the human and bovine enamel showed apparently similar aspects (1). Although these studies show similarity in morphology, other studies $(5,14)$ have demonstrated that bovine dentin has some different structural aspects from those reported for human dentin, mainly related to the diameter of dentinal tubules and to the thickness of peritubular dentin at the several depths (14). However, as the fracture strength is a macroscopic test, small differences between the structures do not seem to produce significant influence on the final strength. Moreover, as bovine incisor was ground with silicon carbide paper to get an occlusal platform up to $6 \mathrm{~mm}$ below the cementoenamel junction (CEJ), its size in relation to human teeth was standardized and allowed the use of mid-depth dentin only. These aspects could explain the similar fracture strength between bovine and human teeth.

When performing mechanical tests, some factors are important to approximate the lab conditions to the clinical situation as much as possible, such as the root embedment method to simulate the periodontal membrane, the loading apparatus, and the mode of load transmission (15). The simulation of the periodontal ligament should be done with an elastomeric material that is able to undergo elastic deformation and reproduce the accommodation of the tooth in the alveolus, providing no concentration of stresses in the cervical region of the tooth (10). Moreover, simulation of the periodontal ligament is highly influential on the fracture pattern (10). In this experiment, a polyether impression material was used in association with a polystyrene resin as an adequate method for fracture strength tests $(10,16)$. The method used for loading is another important factor. The use of a 6-mm steel sphere for fracture strength testing, as suggested by Dietschi et al., 1990 (17) and Soares et al., 2004 (16), has been proven ideal for molars because it contacts the functional and nonfunctional cusps in positions close to those found clinically.

Analyzing the effect of fiber reinforcement inclusion on $\mathrm{Cpd}$, it was found that fracture strength increased considerably by adding fiberglass reinforcement, in both human and bovine groups. The fiber used in this study is a structure of intertwined fiberglass impregnated with composite resin, indicated for direct use in dental office. Impregnation of reinforcing fibers with the resin allows fibers to come into with polymer matrix. This is a prerequisite for bonding of fibers to polymer matrix, and thus for strength of the composite. In loading the Cpd from the occlusal surface, the occlusal side of the Cpd undergoes compression stress (7) and at the gingival surface tensile stresses was maximal and concentrated in the connection areas, being the most critical areas (18). The remaining tissues of the abutment teeth were subjected mainly to compressive or extremely low tensile forces (18). The inclusion of fibers at the tensile side of composite resin specimens improves flexure properties $(8,19)$, what can justify the highest values of fiberreinforced composite inlay $\mathrm{Cpd}$ fracture strength for both bovine and human groups. The efficient location for fiber reinforcement is at the tensile sites, such as in the base of the pontic $(8,18)$.

Fiber-reinforced inclusion on composite allows better stress distribution and dissipation in the structure in which it had been incorporated, thus decreasing and 
homogenizing stress transmission to the supporting teeth $(18,19)$. In theory, the reinforcing effect of fiber fillers is not only based on stress transfer from polymer matrix to fibers but also on the behavior of individual fibers as crack stoppers (20). The ability of fiberglass to slow or arrest crack propagation (8) is another reason that may result in an increase on the fracture strength of composite fiber-reinforced partial denture. It is important to stand out that system success depends on the cohesiveness between the fibers and the surrounding resin matrix, which should ensure uniformity of stress transfer from the matrix to the fibers.

In addition to discussing fracture strength values, it may also be important to analyze the failure modes in each experimental group. The failure modes verified for bovine and human groups was similar. In groups without fiberglass reinforcement, the failure modes were more severe than in those with fiberglass reinforcement, which facilitates the repair because no involvement of the junction with retainers was found.

Further research is needed to evaluate the effect of ageing in water or saliva on fiberglass reinforcement. Future studies should also focus on determining the effect of unidirectional fibers inclusion in the region of highest tensile stress on fracture strength of $\mathrm{Cpd}$, since the Krenschel's factor, which means the effectiveness of the woven fiber reinforcement, is lower for the woven fiber reinforcement than for the unidirectional fiber reinforcement.

The analysis of the failure modes reinforces the idea that the fiberglass acts as a crack stoppers and brings better distribution and dissipation of stresses, causing fracture in its long axis. It is important to emphasize that the absence of dental fracture observed in this study supports the use of fiberglass-reinforced composite partial dentures as an adequate option for oral rehabilitation as an interim restoration or as a social alternative with low cost.

The fracture strength of composite partial dentures increased significantly by adding fiberglass reinforcement, in both human and bovine groups. In addition, bovine teeth can be used as substitutes for human teeth in these types of fracture strength tests.

\section{RESUMO}

Este estudo avaliou a utilização de dentes bovinos como substituto de dentes humanos em testes de resistência à fratura de próteses adesivas de resina composta $(\mathrm{Cpd})$, com e sem fibra de reforço. Oitenta dentes foram selecionados sendo 40 incisivos bovinos, 20 pré-molares humanos e 20 molares. Incisivos bovinos foram desgastados para obter plataforma, simulando superfície oclusal de molares humanos. Dentes em pares foram incluídos em resina de poliestireno, simulando o ligamento periodontal. As amostras foram divididas em 4 grupos: B-Cpd-Fg, dentes bovinos restaurados com reforço de fibra de vidro, Fg; B-Cpd$\mathrm{NFg}$, dentes bovinos restaurados com Cpd sem Fg; H-Cpd-Fg, dentes humanos restaurados com Cpd Fg e H-Cpd-NFg, dentes humanos restaurados com $\mathrm{Cpd}$ sem Fg. O Cpd foi fixado adesivamente e submetido a carga de compressão axial no centro do pôntico com velocidade de $0,5 \mathrm{~mm} / \mathrm{min}$ até a fratura. Padrões de fratura foram classificados. Os dados foram submetidos ANOVA fatorial e teste de Tukey $\operatorname{HSD}(\alpha=0,05)$. O tipo de dente não teve nenhuma influência na resistência à fratura e modo de fratura. A inclusão de fibra de vidro aumentou significativamente a resistência à fratura. Os padrões de fratura foram mais reparáveis nos grupos com fibra de reforço. Os dentes bovinos podem ser usados como substituto para dentes humanos nesses tipos de testes de resistência à fratura.

\section{ACKNOWLEDGEMENTS}

The authors are grateful to the Technical School of Health, Federal University of Uberlândia, and to FAPEMIG for financial support.

\section{REFERENCES}

1. Reis AF, Giannini M, Kavaguchi A, Soares CJ. Comparison of microtensile bond strength to enamel and dentin of human, bovine, and porcine teeth. J Adhes Dent 2004;6:117-121.

2. Fonseca RB, Haiter-Neto F, Fernandes-Neto A, Barbosa GAS, Soares CJ. Radiodensity of enamel and dentin of human, bovine and swine teeth. Arch Oral Biol 2004;49:919-922.

3. Saunders WP. The shear impact retentive strengths of four dentin bonding agents to human and bovine dentin. J Dent 1988;16:233238.

4. Schilke R, Lisson JA, Bau O, Geurtsen W. Comparison of the number and diameter of dentinal tubules in human and bovine dentine by scanning electron microscopic investigation. Arch Oral Biol 2000;45:355-361

5. Tagami J, Tao L, Pashley DH, Horner JA. The permeability of dentine from bovine incisors in vitro. Arch Oral Biol 1989;34:773777.

6. Rosentritt M, Behr M, Lang R, Handel G. Experimental design of FPD made of all-ceramics and fibre-reinforced composite. Dental Materials 2000;16:159-165.

7. Vallittu PK. The effect of glass fiber reinforcement on the fracture resistance of a provisional fixed partial denture. J Prosthet Dent 1998;79:125-130.

8. Dyer SR, Lassila LV, Jokinen M, Vallittu PK. Effect of fiber position and orientation on fracture load of fiber-reinforced composite. Dent Mater 2004;20:947-955.

9. Fahmy NZ, Sharawi A. Effect of two methods of reinforcement on the fracture strength of interim fixed partial dentures. J Prosthodont 2009; 18:512-520.

10. Soares CJ, Pizi EC, Fonseca RB, Martins LR. Influence of root embedment material and periodontal ligament simulation on fracture resistance tests. Braz Oral Res 2005;19:11-16.

11. da Silva GR, Simamoto-Júnior PC, da Mota AS, Soares CJ. Mechanical properties of light-curing composites polymerized with different laboratory photo-curing units. Dent Mater J 2007;26:217- 
223.

12. Dong CC, McComb D, Anderson JD, Tam LE. Effect of mode of polymerization of bonding agent on shear bond strength of autocured resin composite luting cements. J Can Dent Assoc 2003;69:229-234.

13. Suga S, Kondo M, Onodera A, Kubota Y, Ohtsuka M. Electron microprobe analyses on the distributions of $\mathrm{Cl}, \mathrm{Mg}, \mathrm{Na}$, in the enamels of various animals. Jpn J Oral Biol 1971;13:85-94.

14. Dutra-Correa M, Anauate-Netto C, Arana-Chavez VE. Density and diameter of dentinal tubules in etched and non-etched bovine dentine examined by scanning electron microscopy. Arch Oral Biol 2007;52:850-855.

15. Burke FJ, Wilson NH, Watts DC. The effect of cavity wall taper on fracture resistance of teeth restored with resin composite inlays. Oper Dent 1993;18:230-236.

16. Soares CJ, Martins LR, Pfeifer JM, Giannini M. Fracture resistance of teeth restored with indirect-composite and ceramic inlay systems. Quintessence Int 2004;35:281-286.
17. Dietschi D, Maeder M, Meyer JM, Holz J. In vitro resistance to fracture of porcelain inlays bonded to tooth. Quintessence Int 1990;21:823-831.

18. Magne P, Perakis N, Belser UC, Krejci I. Stress distribution of inlay-anchored adhesive fixed partial dentures: a finite element analysis of the influence of restorative materials and abutment preparation design. J Prosthet Dent 2002;87:516-527.

19. Nagata K, Takahashi H, Ona M, Hosomi H, Wakabayashi N, Igarashi Y. Reinforcement effects of fiberglass on telescopic dentures using a three-dimensional finite element analysis and fracture test. Dent Mater J 2009;28:649-656.

20. Garoushi S, Vallittu PK, Lassila LV. Fracture resistance of short, randomly oriented, glass fiber-reinforced composite premolar crowns. Acta Biomater 2007;3:779-784.

Accepted March 13, 2010 